\title{
Efficient synthesis of new pyrazoles derivatives via functionalized aryl-sydnones
}

\author{
Presented by
}

OUMESSAOUD Asmaa

Thesis Director :

Thesis Co-director :

Thesis Co-director :
Pr. H. OUCHETTO

Pr. M. D. PUJOL

Pr. M. KHOUILI
Université Sultan Moulay Slimane, Béni-Mellal, Maroc

Universitat de Barcelona, Facultat de Farmàcia, Spain

Université Sultan Moulay Slimane, Béni-Mellal, Maroc 


\section{Plan of the presentation}

INTRODUCTION

EFFICIENT SYNTHESIS OF NEW PYRAZOLES DERIVATIVES VIA FUNCTIONALIZED ARYL-SYDNONES

$\square$ Synthesis of pyrazoles via cycloaddition 1,3 dipolaire of sydnone

$\square$ Synthesis of 1,3,4-trisubstituted pyrazoles derivatives via cross coupling

CONCLUSION AND PERSPECTIVE 


\section{INTRODUCTION}

$>$ The pyrazole derivatives constitue an interesting class of organic compound with diverse chemical applications. Indeed, several classes of drugs carrying the pyrazole fragment have been used in therapeutic chemistry. 


\section{INTRODUCTION}

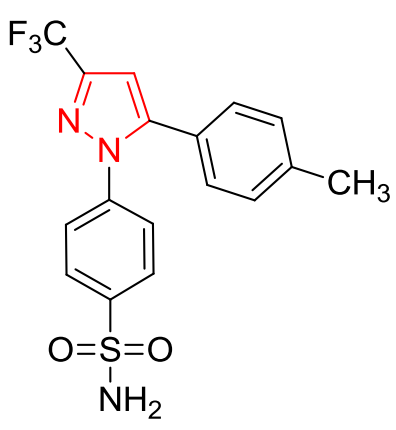

Celecoxib

(anti-inflammatory)

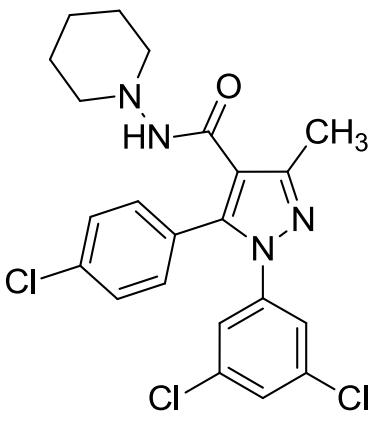

Rimonabant (anti-obesity)

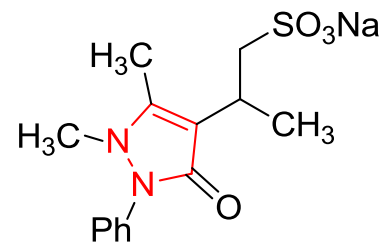

Métamizole

(analgesic)

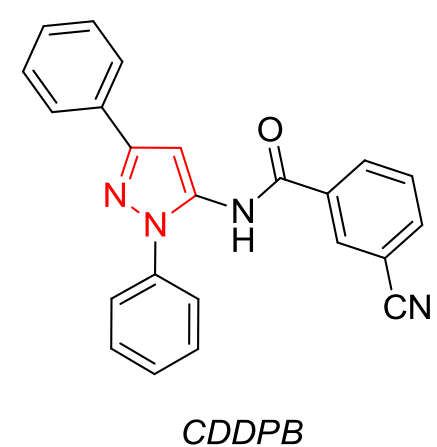

(anti-psychotic)
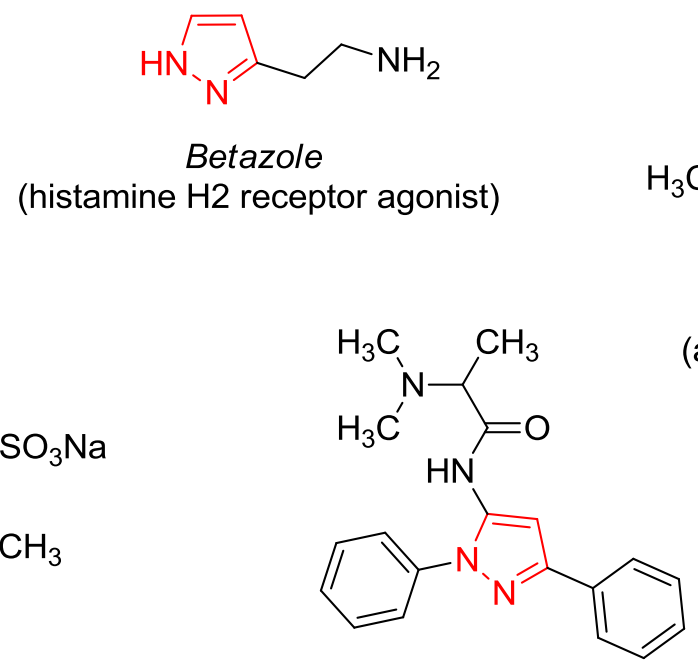

Difénamizole

(analgesic)

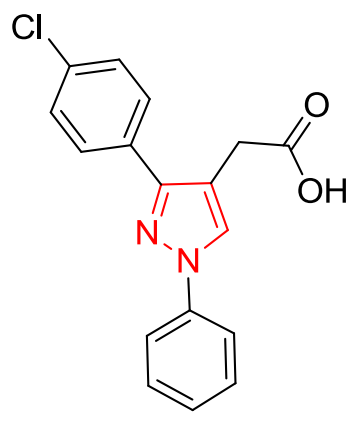

Lonazolac

(anti-inflammatory)

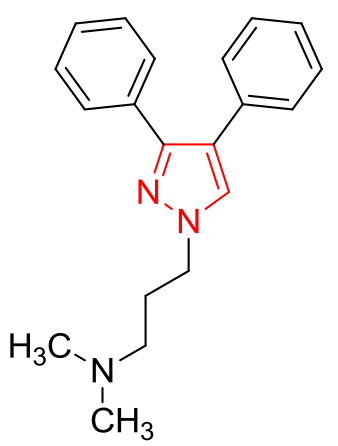

Fezolamine (anti-depressant) 


\section{INTRODUCTION}

\section{Panda (2012)}

N. Panda, A. K. Jena, J. Org. Chem, 2012, 77, 9401-9406,

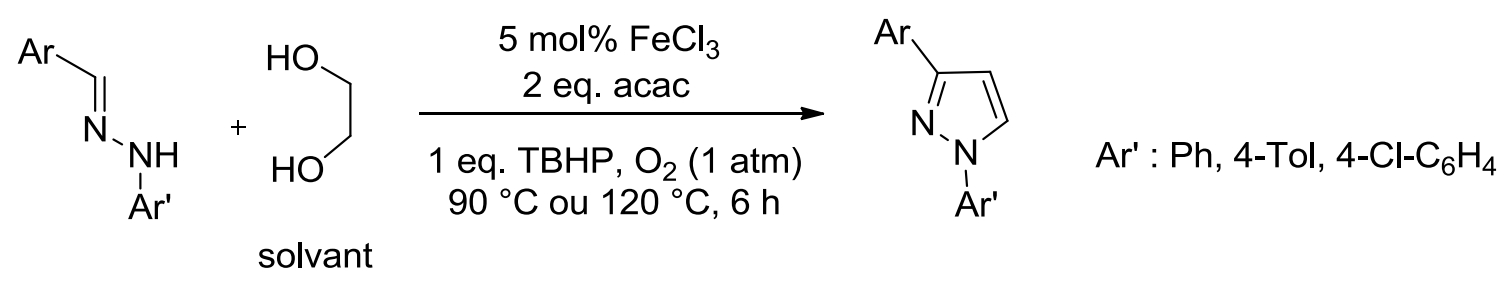

Yield : 51-85\%

Chang, Yu (2014)

X. Zhang, J. Kang, P. Niu, J. Wu, W. Yu, J. Chang, J. Org. Chem, 2014, 79, 10170-10178.

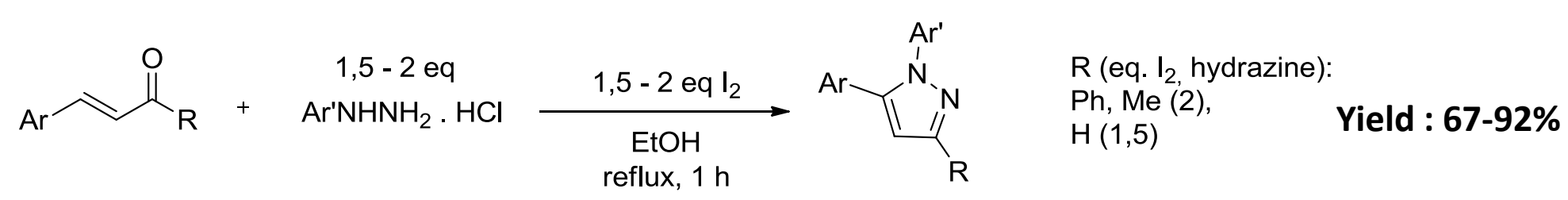




\section{EFFICIENT SYNTHESIS OF NEW PYRAZOLES DERIVATIVES VIA}

\section{FUNCTIONALIZED ARYL-SYDNONES}

$\square$ Synthesis of pyrazoles via cycloaddition 1,3 dipolaire of sydnone

$\square$ Synthesis of 1,3,4-trisubstituted pyrazoles derivatives via cross coupling 


\section{EFFICIENT SYNTHESIS OF NEW PYRAZOLES DERIVATIVES VIA FUNCTIONALIZED ARYL-SYDNONES}

Synthesis of pyrazoles via cycloaddition 1,3 dipolaire of sydnone

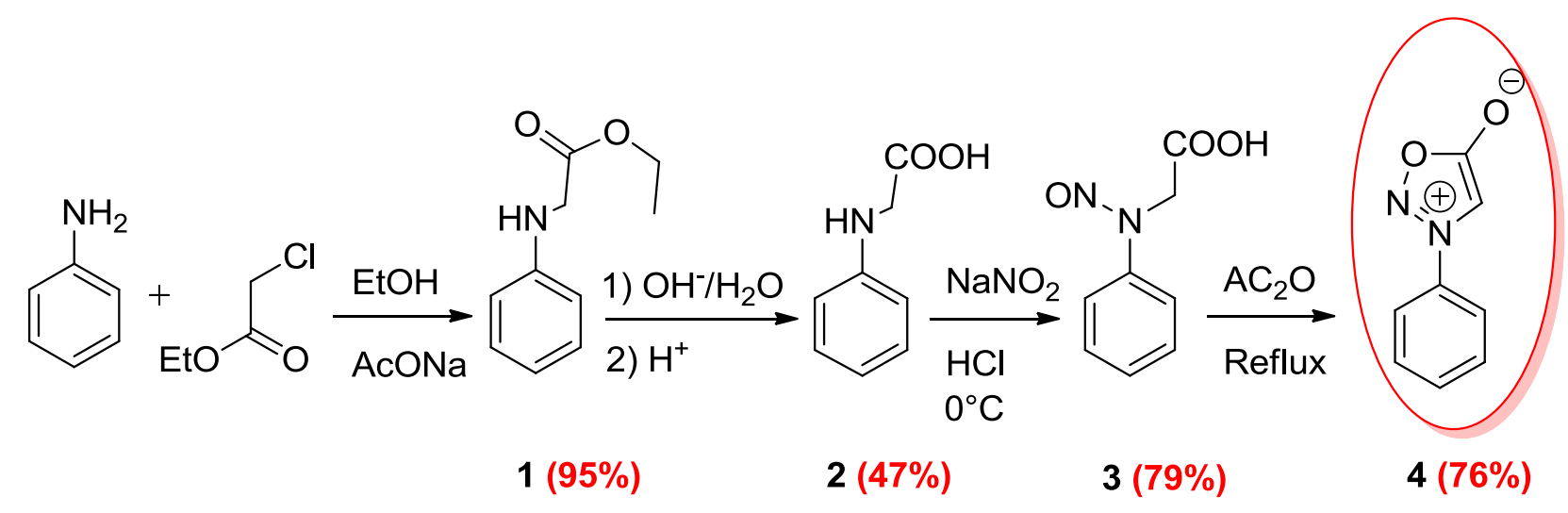

Patel, Y. M.; Patel, K. C. J. Saudi Chem. Society 2012, 02, 5. 


\section{EFFICIENT SYNTHESIS OF NEW PYRAZOLES DERIVATIVES VIA FUNCTIONALIZED ARYL-SYDNONES}

Synthesis of pyrazoles via cycloaddition 1,3 dipolaire of sydnone

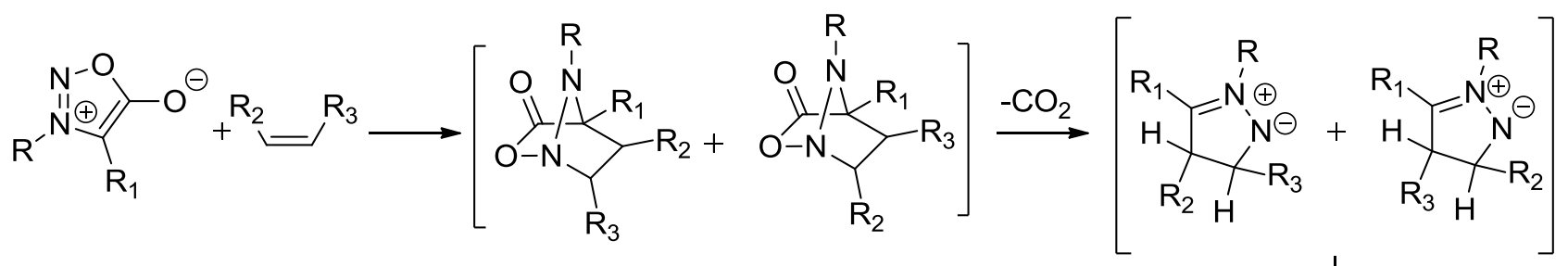

$\mathrm{R}=\mathrm{Ph}, \mathrm{Bn}, 3-$ pyridyl-

$\mathrm{R}_{1}=\mathrm{H}, \mathrm{Me}$
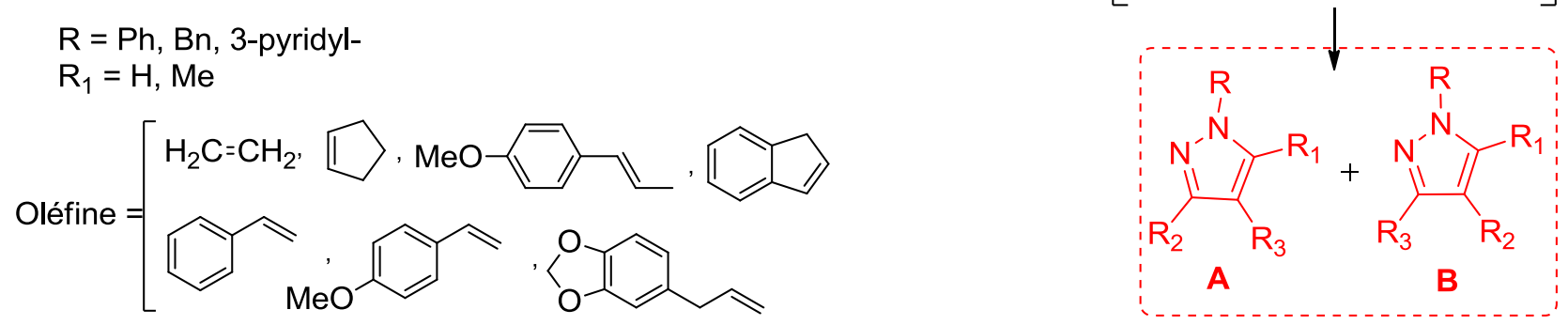

Huisgen, R.; Gotthardt, H.; Grashley, R. Angew. Chem. Int. Ed. Engl. 1962, 1, 49. 


\section{EFFICIENT SYNTHESIS OF NEW PYRAZOLES DERIVATIVES VIA FUNCTIONALIZED ARYL-SYDNONES}

Synthesis of pyrazoles via cycloaddition 1,3 dipolaire of sydnone

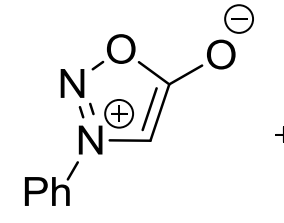

Sydnone
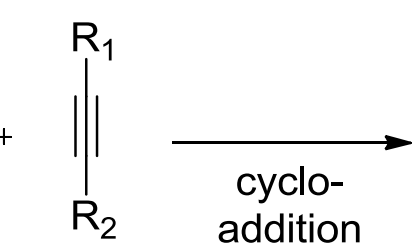

addition
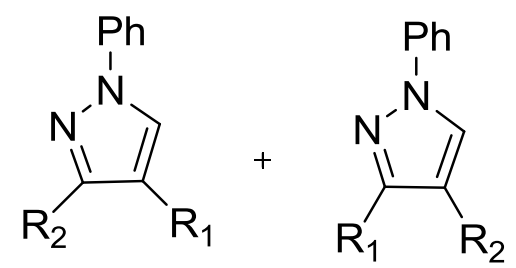

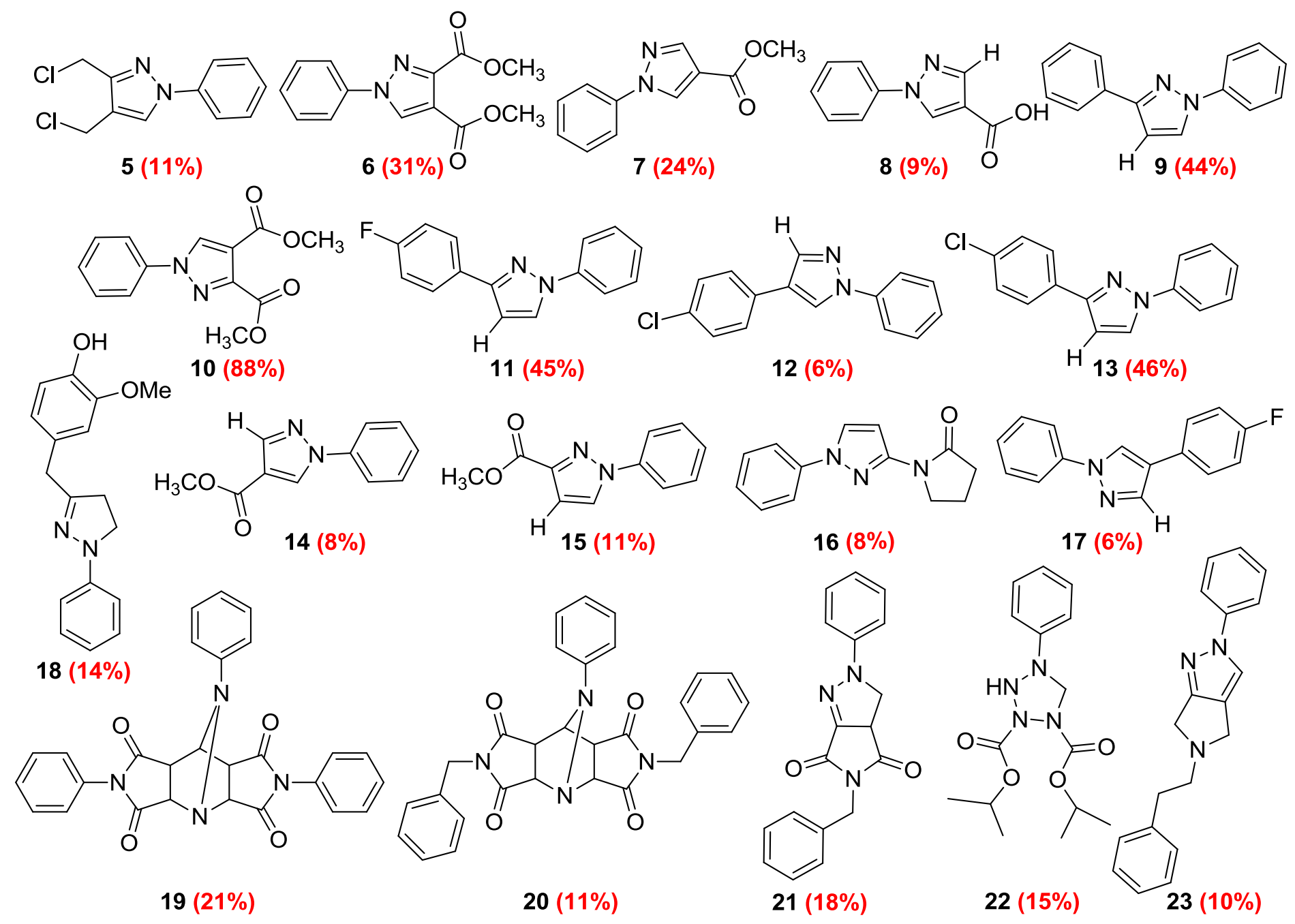


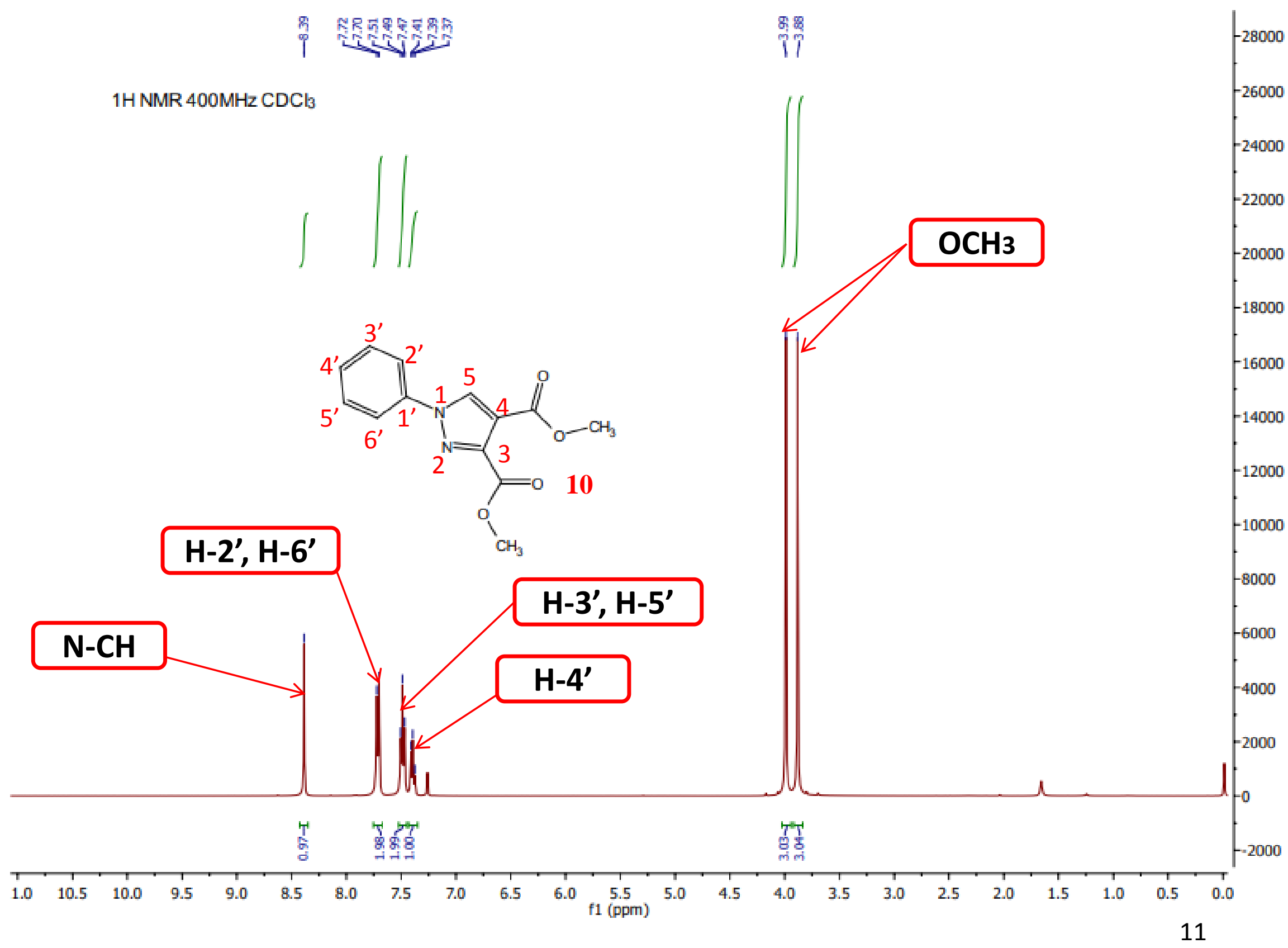




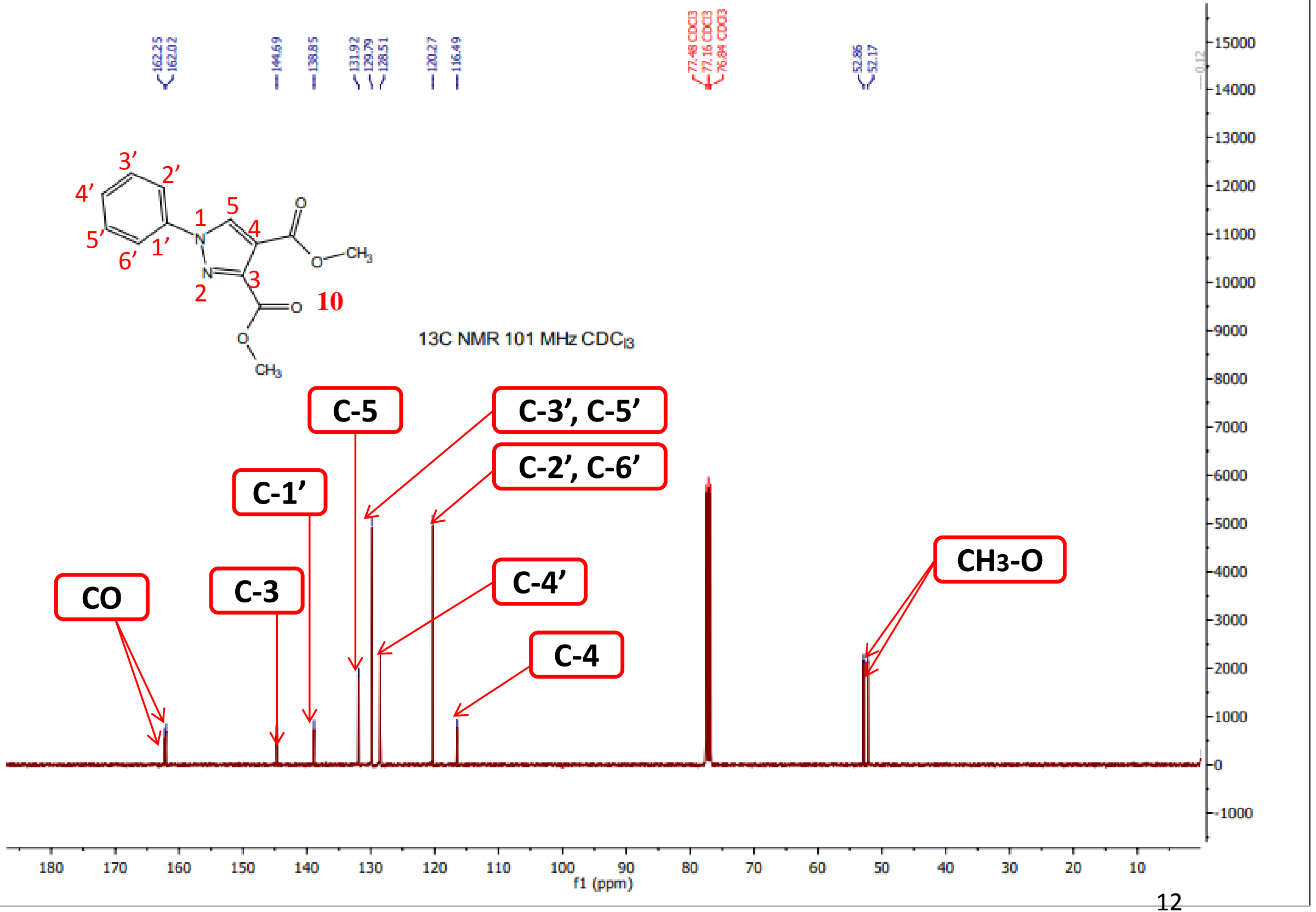




\section{EFFICIENT SYNTHESIS OF NEW PYRAZOLES DERIVATIVES VIA}

\section{FUNCTIONALIZED ARYL-SYDNONES}

$\square$ Synthesis of pyrazoles via cycloaddition 1,3 dipolaire of sydnone

$\square$ Synthesis of 1,3,4-trisubstituted pyrazoles derivatives via cross coupling 


\section{EFFICIENT SYNTHESIS OF NEW PYRAZOLES DERIVATIVES VIA}

FUNCTIONALIZED ARYL-SYDNONES

Synthesis of 1,3,4-trisubstituted pyrazoles derivatives via cross coupling

Objectif

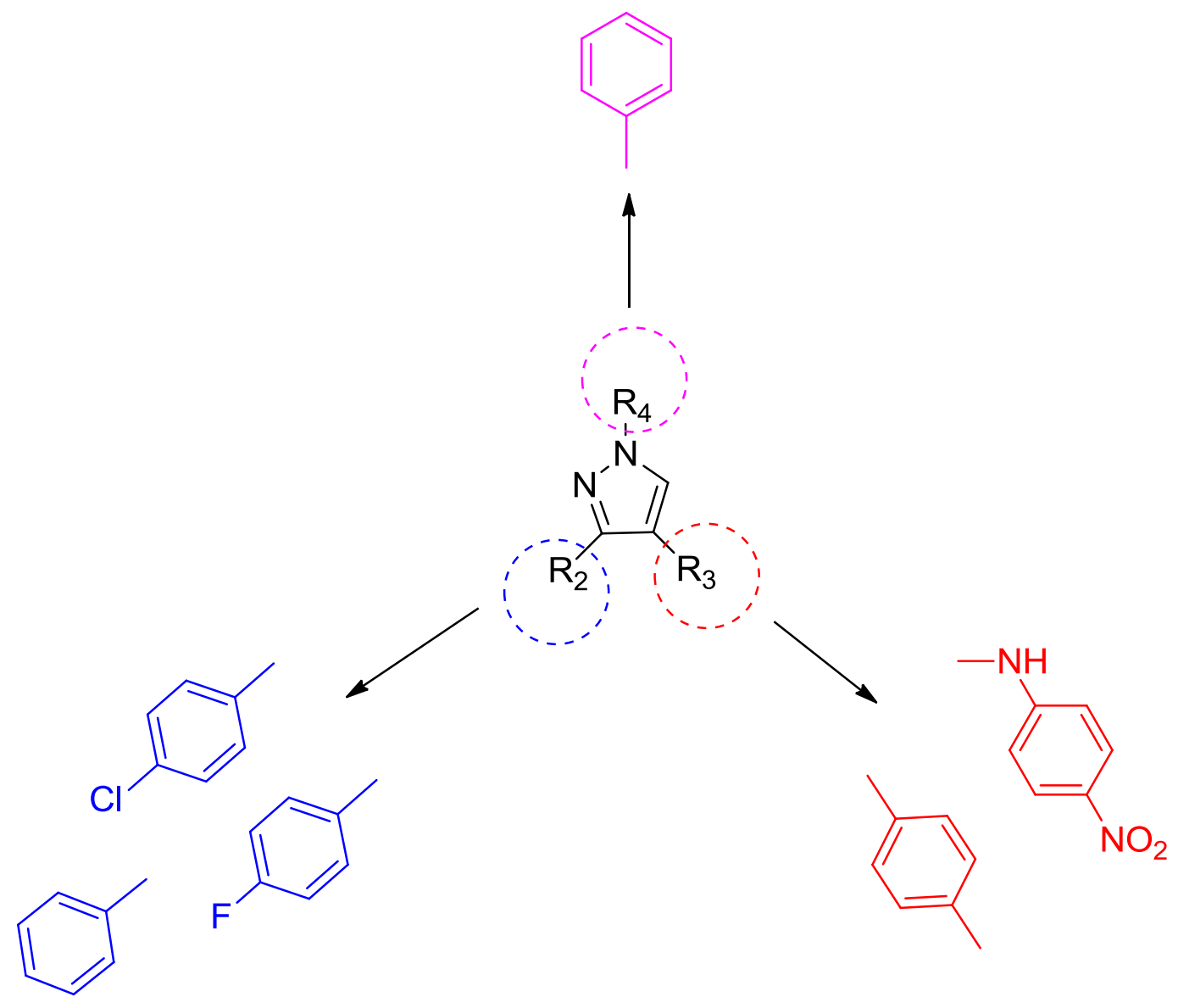


EFFICIENT SYNTHESIS OF NEW PYRAZOLES DERIVATIVES VIA FUNCTIONALIZED ARYL-SYDNONES

Synthesis of 1,3,4-trisubstituted pyrazoles derivatives via cross coupling
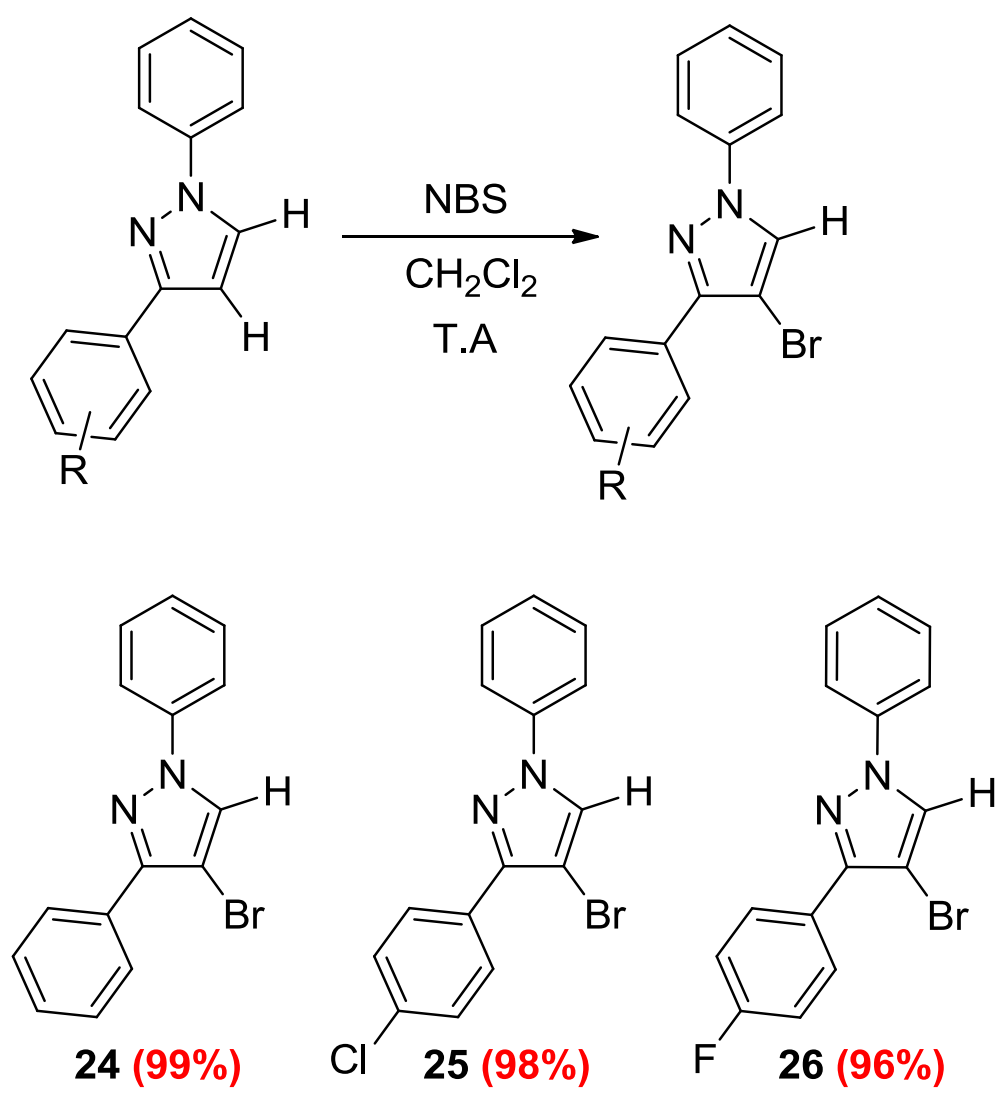


\section{EFFICIENT SYNTHESIS OF NEW PYRAZOLES DERIVATIVES VIA FUNCTIONALIZED ARYL-SYDNONES}

Synthesis of 1,3,4-trisubstituted pyrazoles derivatives via cross coupling
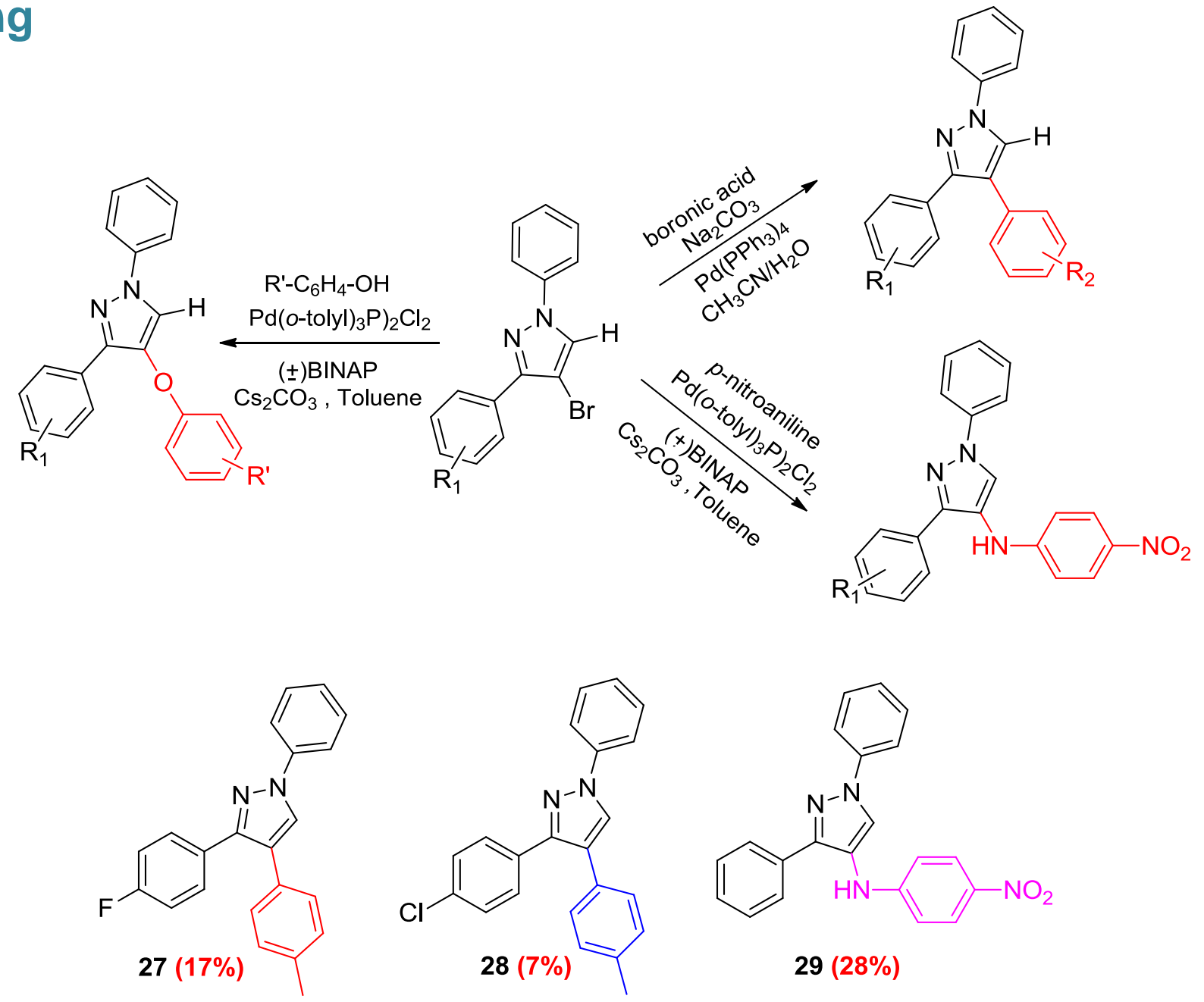


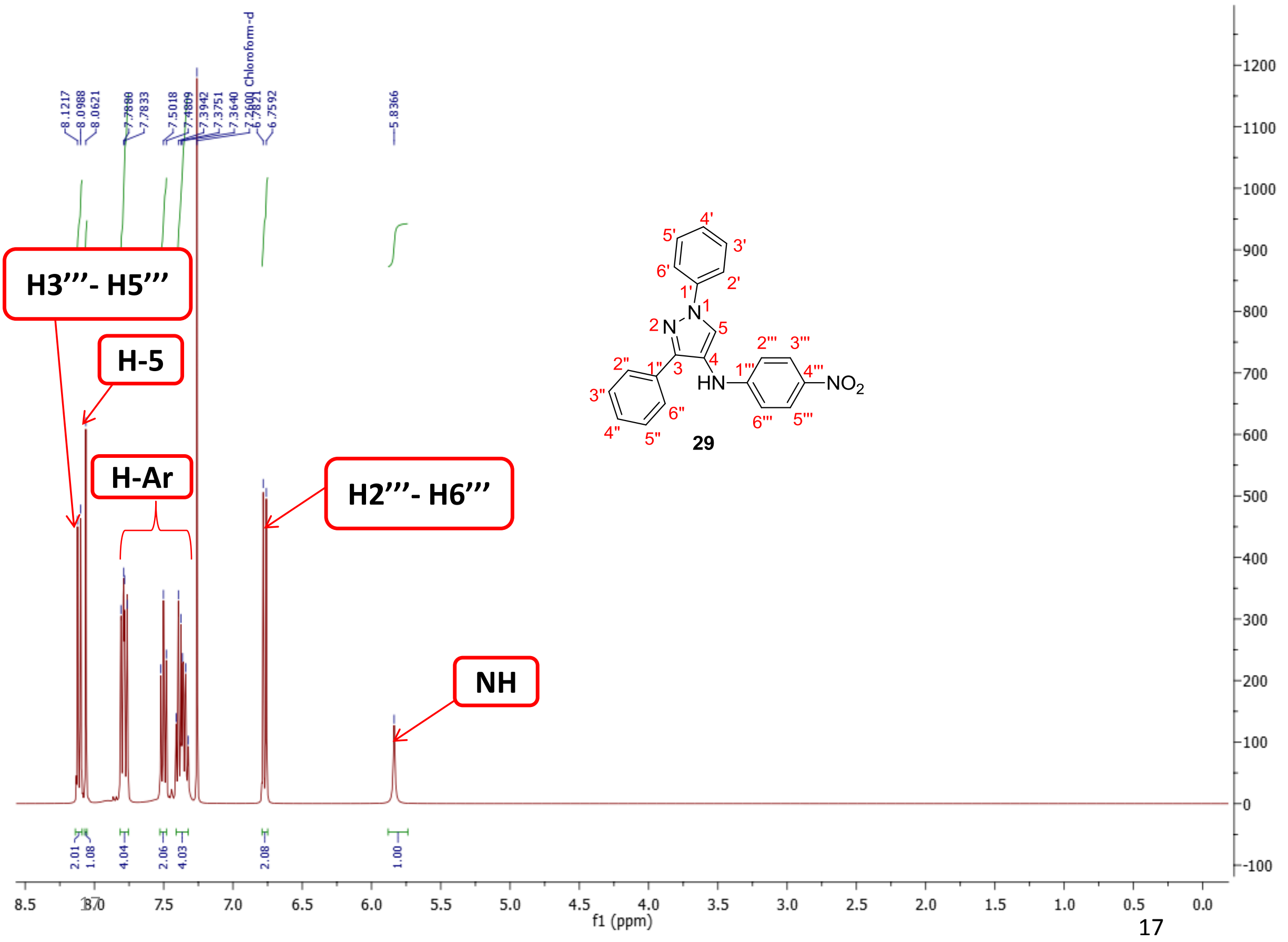




\section{CONCLUSION AND PERSPECTIVE}

$>$ Develop a new method of synthesizing the substituted pyrazole skeleton from sydnone.

Perspective

$\square$ Improve the reaction yield

$\square$ Investigation of the biological activity of the obtained substances 
Thank you for your attention 